\title{
A combination Alzheimer's therapy targeting BACE1 and neprilysin in 5XFAD transgenic mice
}

Latha Devi ${ }^{1}$ and Masuo Ohno ${ }^{1,2^{*}}$

\begin{abstract}
Background: Accumulating evidence indicates that partial inhibition of $\beta$-site APP-cleaving enzyme 1 (BACE1), which initiates amyloid- $\beta(A \beta)$ production, mitigates Alzheimer's disease (AD)-like pathologies and memory deficits in a battery of transgenic mouse models. However, our previous investigations suggest that therapeutic BACE1 suppression may be beneficial only if targeted on earlier stages of AD and encounter dramatic reductions in efficacy during disease progression. This study was designed to test the possibility that a combination approach, aimed at inhibiting BACE1 and boosting neprilysin (a major A $\beta$-degrading enzyme) activities, may be able to mechanistically overcome the limited efficacy of anti-A $\beta$ therapy in advanced AD.

Results: After crossbreeding between BACE1 heterozygous knockout (BACE ${ }^{+/-}$), neprilysin transgenic (NEP) and 5XFAD mice, we analyzed the resultant mice at 12 months of age when 5XFAD controls showed robust amyloid- $\beta$ (A 3 ) accumulation and elevation of BACE1 expression ( 2 folds). Although haploinsufficiency lowered BACE1 expression by $\sim 50 \%$ in concordance with reduction in gene copy number, profound $\beta$-amyloidosis, memory deficits and cholinergic neuron death were no longer rescued in BACE1 ${ }^{+/-}$. 5 XFAD mice concomitant with their persistently upregulated BACE1 (i.e., equivalent to wild-type control levels). Notably, neprilysin overexpression not only prevented $A \beta$ accumulation but also suppressed the translation initiation factor elF2a-associated elevation of BACE1 and lowered levels of the $\beta$-secretase-cleaved C-terminal fragment of APP (C99) in NEP. 5XFAD mice. Interestingly, these markers for $\beta$-amyloidogenesis in $B A C E 1^{+/-}$. NEP. 5XFAD mice were further reduced to the levels reflecting a combination of single BACE1 allele ablation and the abolishment of translational BACE1 upregulation. However, since neprilysin overexpression was striking ( 8-fold relative to wild-type controls), memory impairments, cholinergic neuronal loss and $\beta$-amyloidosis were similarly prevented in NEP. 5XFAD and BACE1 ${ }^{+-}$. NEP . 5XFAD mice.
\end{abstract}

Conclusions: Our findings indicate that robust overexpression of neprilysin is sufficient to ameliorate AD-like phenotypes in aged 5XFAD mice. We also found that A $\beta$-degrading effects of overexpressed neprilysin can block deleterious BACE1-elevating mechanisms that accelerate $A \beta$ production, warranting further study to test whether interventions moderately activating neprilysin may be useful for boosting the limited efficacy of therapeutic BACE1 inhibition in treating $A D$ with established $A \beta$ pathology.

Keywords: Alzheimer's disease, Amyloid- $\beta$, $\beta$-Secretase, BACE1, Neprilysin, C99, Learning and memory, Fear conditioning, Cholinergic neuron, 5XFAD

\footnotetext{
* Correspondence: mohno@nki.rfmh.org

${ }^{1}$ Center for Dementia Research, Nathan Kline Institute, 140 Old Orangeburg Road, Orangeburg, NY 10962, USA

2Department of Psychiatry, New York University Langone Medical Center, New York, NY 10016, USA
}

\section{() Biomed Central}

(c) 2015 Devi and Ohno; licensee BioMed Central. This is an Open Access article distributed under the terms of the Creative Commons Attribution License (http://creativecommons.org/licenses/by/4.0), which permits unrestricted use, distribution, and reproduction in any medium, provided the original work is properly credited. The Creative Commons Public Domain Dedication waiver (http://creativecommons.org/publicdomain/zero/1.0/) applies to the data made available in this article, unless otherwise stated. 


\section{Background}

The $\beta$-secretase, called $\beta$-site amyloid precursor proteincleaving enzyme 1 (BACE1), was identified as an aspartyl protease that initiates the production of amyloid- $\beta$ (A $\beta)$ peptides [1]. Given pathogenic roles of $\mathrm{A} \beta$ in $\mathrm{AD}[2,3]$, $\mathrm{BACE} 1$ is one of the prime therapeutic targets to prevent or treat this devastating neurodegenerative disorder [4-7]. It has been demonstrated that homozygous BACE1 knockout $\left(\mathrm{BACE}^{-/-}\right)$prevents the development of AD-like pathologies and memory deficits in different transgenic lines of amyloid precursor protein (APP)-overexpressing mice [8-11]. Furthermore, BACE1 haploinsufficiency $\left(\mathrm{BACE}^{+/-}\right.$; i.e., a therapeutic relevant model for $50 \%$ suppression) [12-18] as well as chronic treatments with bioavailable small-molecule BACE1 inhibitors (e.g., GRL-8234 and TAK-070) [19-21] has been reported to partially reduce cerebral $A \beta$ concentrations and mitigate amyloid plaque and tau pathologies, cholinergic neuron loss, mitochondrial dysfunction, hippocampal synaptic failure, and memory deficits in APP mice. However, some of these studies raise concern that the beneficial outcomes associated with partial BACE1 inhibition may decline during the progression of $\mathrm{AD}[11,12,15,16,18,21]$.

It has been demonstrated that $\mathrm{A} \beta$ accumulation induces BACE1 elevation in neurons surrounding the amyloid core of plaques, which in turn further accelerates $A \beta$ production and plaque growth in brains of the 5XFAD mouse model and AD patients [22-26]. Meanwhile, previous studies with neprilysin transgenic and knockout mice have clearly shown that neprilysin-dependent degradation of $A \beta$ is critical for suppressing plaque development [27-30]. Notably, we found that partial suppression of BACE1 with haploinsufficiency or the $\beta$-secretase inhibitor GRL-8234 was no longer able to exert beneficial effects including memory improvements in advanced stages of 5XFAD mice ( $\geq 12$ months of age) suffering from robust $A \beta$ deposition, since it failed to reverse BACE1 elevation and neprilysin reduction in the brain $[15,18,21]$. Therefore, our results suggest that monotherapeutic approaches targeting BACE1 may not be sufficient to block a detrimental feed-forward link between neprilysin reduction, increased levels of $A \beta$ plaque formation and BACE1 elevation during the course of AD progression. In this study, we tested whether a combination strategy that boosts $A \beta$ degradation (neprilysin overexpression) and arrests $A \beta$ production (BACE1 haploinsufficiency) may be useful for mechanistically increasing the limited therapeutic efficacies in 12-month-old 5XFAD mice.

\section{Results}

Effects of BACE1 haploinsufficiency combined with neprilysin overexpression on $\beta$-amyloidogenic processing of APP in aged 5XFAD mice

We used 5XFAD APP/presenilin-1 (PS1) transgenic mice that represent a rapid-onset and aggressive amyloid model based on a combination of five familial AD (FAD) mutations and the consequent acceleration of neurotoxic A 342 production $[9,10,31]$. 5XFAD mice begin to develop visible $A \beta$ deposition as early as 2 months of age and exhibit memory declines on a battery of hippocampusdependent tasks around 6 months concomitant with synaptic dysfunction at the Schaffer collateral-CA1 pathway [9,13,31-38]. We tested the effects of heterozygous BACE1 deletion $\left(\mathrm{BACE}^{+/-}\right)$, neprilysin overexpression (NEP) and their combination $\left(\mathrm{BACE}^{+/-} \cdot \mathrm{NEP}\right)$ in 5XFAD mice at 12 months of age, which show extensive $A \beta$ plaque pathology concomitant with significant BACE1 elevation and neprilysin reduction and are no longer responsive to rescue by BACE1 haploinsufficiency $[15,16,18]$. We first compared the degree of neprilysin overexpression by quantitative immunoblot analysis of brain samples (Figure 1). As previously reported in hAPP-J20 transgenic mice engineered to overexpress neprilysin [29,30], we confirmed robust overexpression of neprilysin $(859 \pm 20 \%)$ in NEP $\cdot 5$ XFAD mice relative to 5XFAD controls. Moreover, we found that the addition of $\mathrm{BACE} 1^{+/-}$gene ablation to these mice (i.e., $\left.\mathrm{BACE}^{+/-} \cdot \mathrm{NEP} \cdot 5 \mathrm{XFAD}\right)$ did not affect overexpression levels of neprilysin $(864 \pm 31 \%)$.

Next, we investigated changes in the $\beta$-amyloidogenic processing of APP (Figure 2). BACE1 expression levels in 12-month-old 5XFAD mice were significantly increased up to $\sim 2$ folds as compared with those in wildtype control mice $(p<0.05)$ (Figure 2A, B). Consistent with our previous results $[15,18]$, although haploinsufficiency reduced BACE1 expression by $\sim 50 \%$ in $5 X F A D$ mice $(p<0.05)$, the residual levels of BACE1 in $\mathrm{BACE} 1^{+/-}$. 5XFAD mouse brains were equivalent to wild-type control levels (i.e., twice the gene copy number). Interestingly, neprilysin overexpression in 5XFAD mice also reversed the upregulation of BACE1 to wild-type levels $(p<0.05)$. Of note, BACE1 levels were indistinguishable between neprilysin transgenic and wild-type control mice (data not shown), excluding the possibility that neprilysin overexpression by itself may directly affect BACE1 expression. A significant

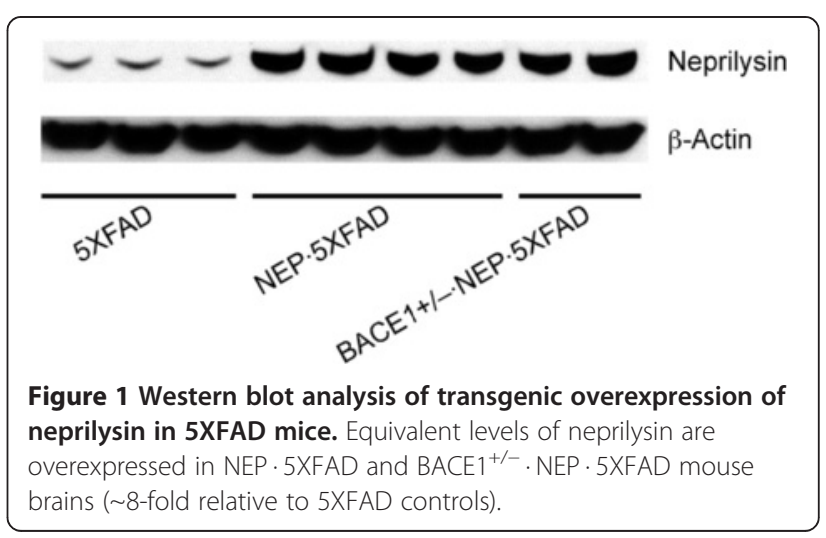




\section{A}

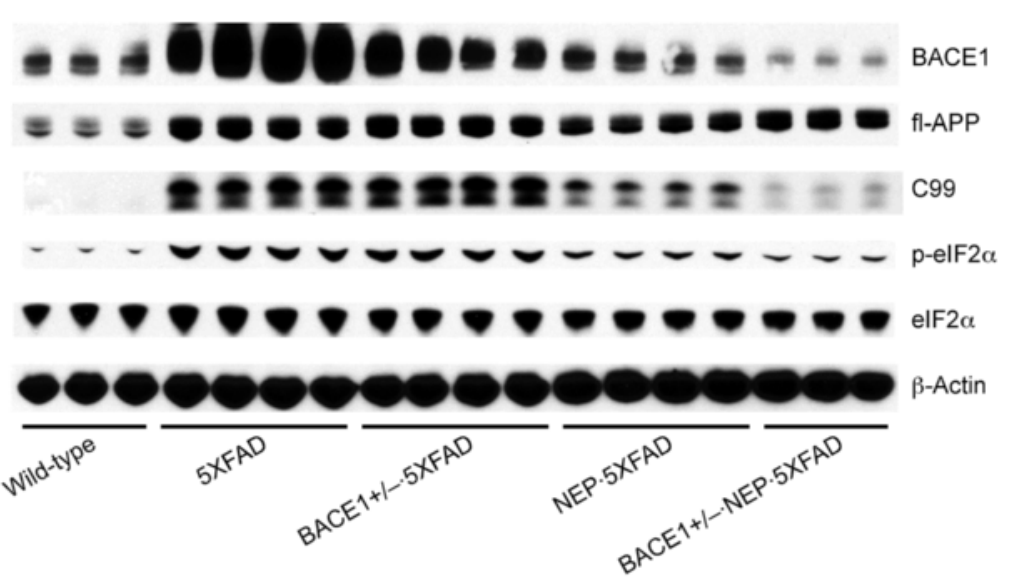

B
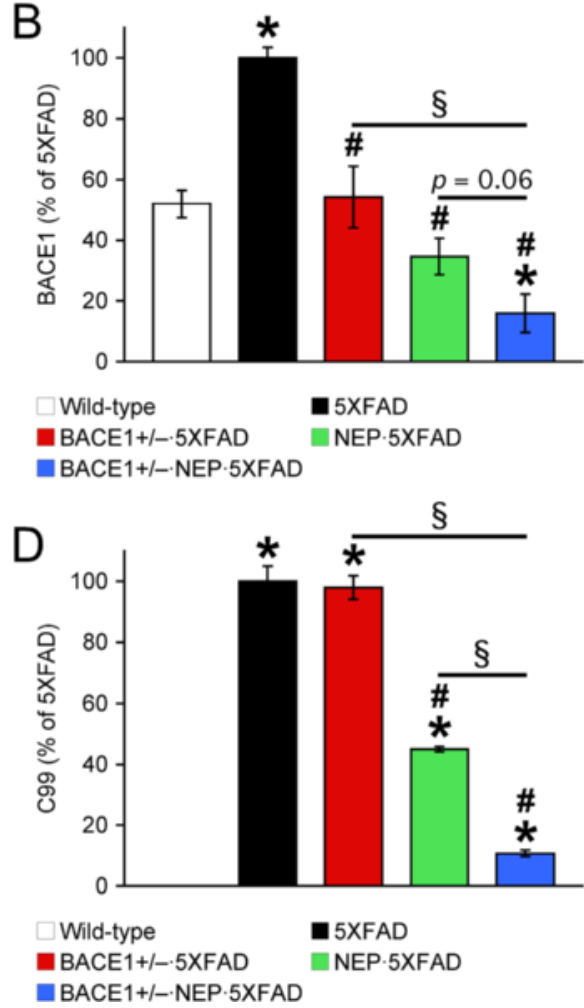

C
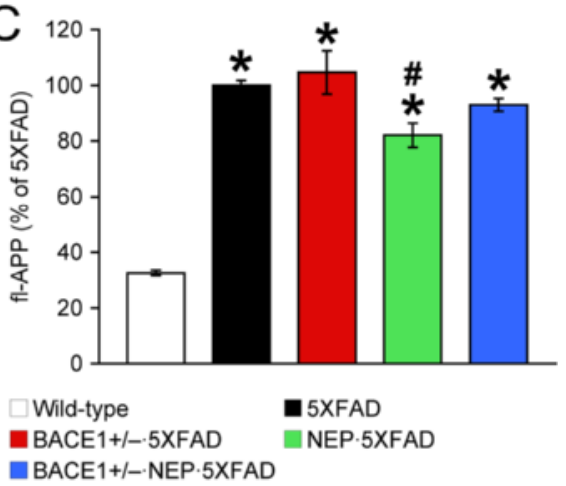

$\mathrm{E}$
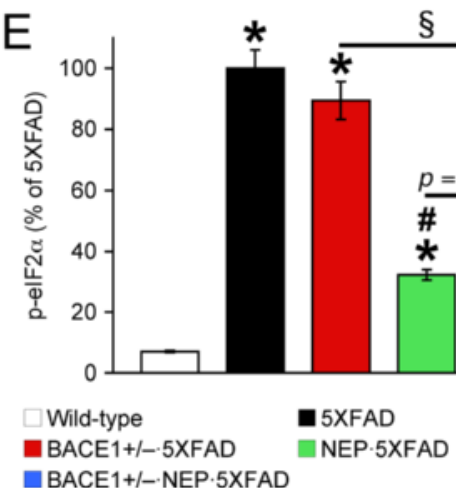

Figure 2 Effects of a combination of BACE1 haploinsufficiency and neprilysin overexpression on $\beta$-amyloidogenic processing of APP in 12-month-old 5XFAD mice. (A) Representative immunoblots of protein extracts from hemibrain homogenates of mice. (B-E) Immunoreactive bands were quantified and expressed as the percentage of 5XFAD control mice ( $n=3-4$ mice per group). Note that BACE1 expression is reduced below wild-type controls in BACE1 ${ }^{+-}$. NEP. 5XFAD mice, as expected by a single BACE1 allele ablation and the complete abolishment of elF2a phosphorylation-dependent translational upregulation. Consequently, the $\beta$-secretase-cleaved C-terminal fragment of APP (C99) is also dramatically reduced in these mice. ${ }^{*} p<0.05$ vs. wild-type, ${ }^{\#} p<0.05 \mathrm{vs}$. 5XFAD, ${ }^{\S} p<0.05 \mathrm{vs}$. BACE ${ }^{+/-}$. NEP. 5XFAD. All data are presented as mean \pm SEM.

reduction or trend toward reduction of BACE1 was observed in $\mathrm{BACE}^{+/-} \cdot \mathrm{NEP} \cdot 5 \mathrm{XFAD}$ mice as compared to $\operatorname{BACE}^{+/-} \cdot$ XXFAD $(p<0.05)$ or NEP.5XFAD $(p=0.06)$ mice, indicating that a combination of BACE1 haploinsufficiency and neprilysin overexpression in 5XFAD mice can further reduce BACE1 expression below wild-type control levels $(p<0.05)$. Meanwhile, overexpression levels of full-length APP were not affected except for the NEP.5XFAD group, which showed a slight but significant decrease compared with 5XFAD controls $(p<0.05)$ (Figure $2 \mathrm{~A}, \mathrm{C})$. The $\beta$-secretase-cleaved Cterminal fragment of APP ( $\beta$-CTF or C99) in 5XFAD mice at 12 months of age was not affected by BACE1 haploinsufficiency, whereas C99 levels in NEP.5XFAD 
mice were significantly lower than those in 5XFAD controls $(p<0.05)$ (Figure 2A, D). Moreover, in accordance with the robust reduction of BACE1 expression, C99 levels were also further reduced in $B A C E 1^{+/-} \cdot \mathrm{NEP}$. 5XFAD mice as compared with $\mathrm{BACE} 1^{+/-} \cdot 5 \mathrm{XFAD}$ and NEP · 5XFAD mice $(p<0.05)$.

Recent findings from our laboratory and others have demonstrated that translational mechanisms through overactivation of the eukaryotic initiation factor- $2 \alpha$ (eIF2 $\alpha$ ) phosphorylation pathway $[15,18,24,39-43]$ rather than transcriptional mechanisms [22,44,45] account for BACE1 elevation found in advanced stages of 5XFAD mice as well as sporadic AD cases. Therefore, we compared levels of phosphorylated eIF2 $\alpha$ (Figure 2A, E) in association with the alterations of BACE1 expression. In agreement with our previous studies [15,18], haploinsufficiency lowered BACE1 expression by $~ 50 \%$ in concordance with the reduction of gene copy number but failed to affect phospho-eIF2 $\alpha$-dependent BACE1-elevating mechanisms in 12-month-old 5XFAD mice; therefore, BACE1 expression in $\mathrm{BACE}^{+/-}$. 5XFAD mice remained upregulated or equivalent to wild-type levels. Importantly, neprilysin overexpression significantly suppressed eIF2 $\alpha$ phosphorylation without affecting total eIF $2 \alpha$ levels in 5XFAD mice $(p<0.05)$, leading to the reversal of translational BACE1 upregulation. Moreover, a combination of BACE1 haploinsufficiency and neprilysin overexpression in 5XFAD mice almost completely blocked eIF2 $\alpha$ phosphorylation, which in turn was able to lower BACE1 expression below wild-type controls in $\mathrm{BACE}^{+/-} \cdot \mathrm{NEP} \cdot$ 5XFAD mice as a consequence of the ablation of a single BACE1 allele and the blockade of translational upregulation.

Effects of BACE1 haploinsufficiency combined with neprilysin overexpression on $\beta$-amyloidosis in aged 5XFAD mice

We further examined how $A \beta$ plaque loads were affected by BACE1 and/or neprilysin manipulations in 5XFAD mice (Figure 3A). In accordance with our previous findings $[15,18]$, we confirmed that BACE1 haploinsufficiency alone was not sufficient to reduce extensive $A \beta$ deposition found in the hippocampus (Figure $3 \mathrm{~B}$ ) or cerebral cortex (Figure $3 \mathrm{C}$ ) of 5XFAD mice at 12 months of age $(n=2)$. In contrast, as reported in the hAPP-J20 mouse model [29,30], transgenic overexpression of neprilysin almost completely prevented $\mathrm{A} \beta$ plaque formation in 5XFAD mice $(p<0.05)$. A combination of BACE1 haploinsufficiency and neprilysin overexpression also similarly blocked plaque development $(p<0.05)$, indicating no further reduction in brain $\mathrm{A} \beta$ burden in $\mathrm{BACE} 1^{+/-}$. NEP . 5XFAD mice as compared with NEP.5XFAD mice. Consistent with $A \beta$ immunostaining, sandwich ELISAs also showed that total $A \beta 42$ levels in $5 \mathrm{M}$ guanidine-extracted brains were significantly and equivalently reduced in NEP.5XFAD and $\mathrm{BACE}^{+/-} \cdot \mathrm{NEP} \cdot 5 \mathrm{XFAD}$ mice $(p<0.05)$, but not in $\mathrm{BACE}^{+/-}$.5XFAD mice, as compared with 5XFAD controls (Figure 3D). Interestingly, ELISAs specific to oligomeric forms of $A \beta$ revealed that all of $B A C E 1^{+/-}$deletion, neprilysin overexpression and their combination induced similar levels of reductions in soluble $A \beta$ oligomers in 5XFAD mice $(p<0.05)$ (Figure 3E).

\section{Effects of BACE1 haploinsufficiency combined with neprilysin overexpression on memory deficits and cholinergic neuron loss in aged 5XFAD mice}

Finally, we examined whether genetic manipulations of BACE1 and/or neprilysin can rescue memory deficits in 5XFAD mice, using the hippocampus-dependent contextual fear conditioning paradigm (Figure 4A). Wildtype control mice exhibited a robust conditioned fear response as assessed by freezing (the absence of all but respiratory movements) when placed back into the conditioning chamber $24 \mathrm{~h}$ after training. 5XFAD mice at 12 months of age showed significantly reduced levels of freezing compared with wild-type controls $(p<0.05)$, whereas contextual memory remained impaired in $\mathrm{BACE}^{+/-} \cdot$.XFAD mice as reported previously [18]. In contrast, contextual memory deficits in 5XFAD mice were rescued almost completely back to wild-type levels in NEP.5XFAD and $\mathrm{BACE} 1^{+/-} \cdot \mathrm{NEP} \cdot 5 \mathrm{XFAD}$ mice $(p<0.05)$. Meanwhile, freezing levels were indistinguishable between wild-type, $\mathrm{BACE} 1^{+/-}, \mathrm{NEP}$ and $\mathrm{BACE}^{+/-} \cdot \mathrm{NEP}$ mice (Figure 4B), demonstrating that $\mathrm{BACE}^{+/-}$reduction, neprilysin overexpression and their combination does not affect baseline memory performances on the non-5XFAD transgenic background.

The septohippocampal cholinergic pathway plays an important role in memory performances including the contextual fear conditioning [46], while cholinergic neuron loss is found in several $\mathrm{AD}$ transgenic mouse models such as 5XFAD and APP23 [15,42,47]. Therefore, we further examined whether BACE1 and/or neprilysin manipulations can rescue neurodegeneration by analyzing cholinergic neurons in the medial septum and the vertical limb of the diagonal band (Ch1/2) that provide the cholinergic innervation to the hippocampus (Figure 4C). Immunostaining for choline acetyltransferase (ChAT: a cholinergic marker) revealed that the number of cholinergic neurons was significantly reduced in 12-month-old 5XFAD mice as compared with that of wild-type controls $(p<0.05)$ (Figure 4D). Consistent with behavioral improvements, ChAT-positive neuron number in NEP - 5XFAD as well as $\mathrm{BACE}^{+/-}$. NEP -5XFAD mice was significantly higher than that of 5XFAD mice $(p<0.05)$ and equivalent to wild-type control levels. In contrast, the number of cholinergic neurons in $\mathrm{BACE}^{+/-}$. 5XFAD mice was as low as that of 5XFAD controls $(n=2)$, as reported in our previous 

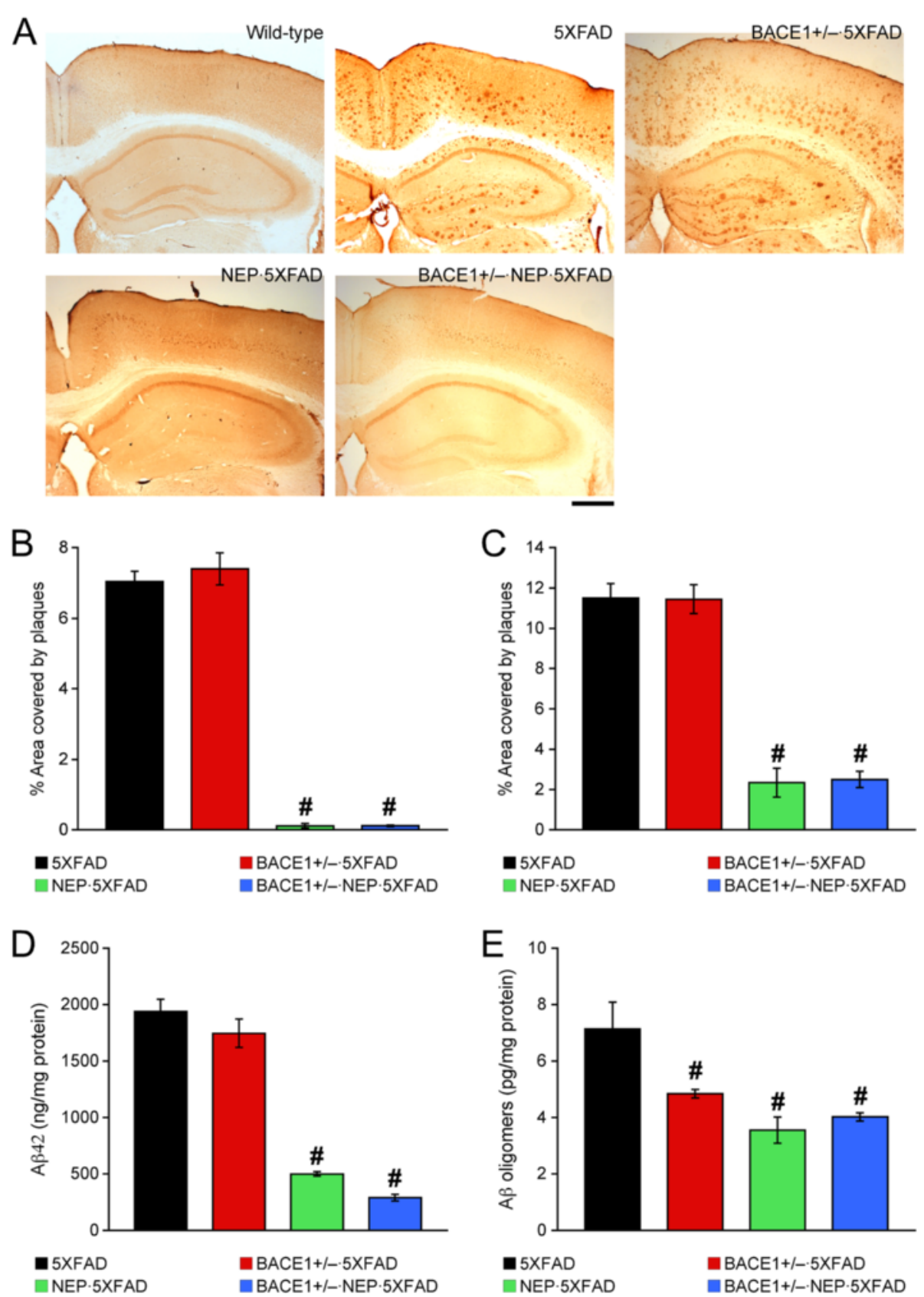

Figure 3 Effects of a combination of BACE1 haploinsufficiency and neprilysin overexpression on $\beta$-amyloidosis in 12-month-old 5XFAD mice. (A) Brain sections were immunostained with the $6 \mathrm{E} 10$ anti-A $\beta$ antibody. Shown are representative photomicrographs of the hippocampal and cortical regions. Scale bar $=500 \mu \mathrm{m}$. (B, C) Percentage area occupied by A $\beta$ deposits in the hippocampus (B) and cerebral cortex (C) was measured for quantification ( $n=2-5$ mice per group). (D, E) Levels of total A 342 in guanidine extracts (D) and soluble A oligomers (E) were quantified by sandwich ELISAs and expressed in nanograms and picograms per milligram of total protein, respectively ( $n=4-6$ mice per group). Significant and equivalent reductions in all A $\beta$ measurements are observed in NEP. 5XFAD and BACE $1^{+-}$. NEP $\cdot 5$ XFAD mice. ${ }^{\#} p<0.05$ vs. 5XFAD. All data are presented as mean \pm SEM.

work [15]. Together, these results indicate that neprilysin overexpression alone or in combination with BACE1 haploinsufficiency can prevent both contextual memory deficits and cholinergic neuron death in advanced stages of 5XFAD mice.

\section{Discussion}

It is widely accepted that both accelerated $A \beta$ production and compromised $A \beta$ clearance underlie the molecular pathogenesis of $\mathrm{AD}[48,49]$. In particular, the $\mathrm{A} \beta$-generating enzyme BACE1 is increased $[15,18,22,42,44,45,50,51]$ while 

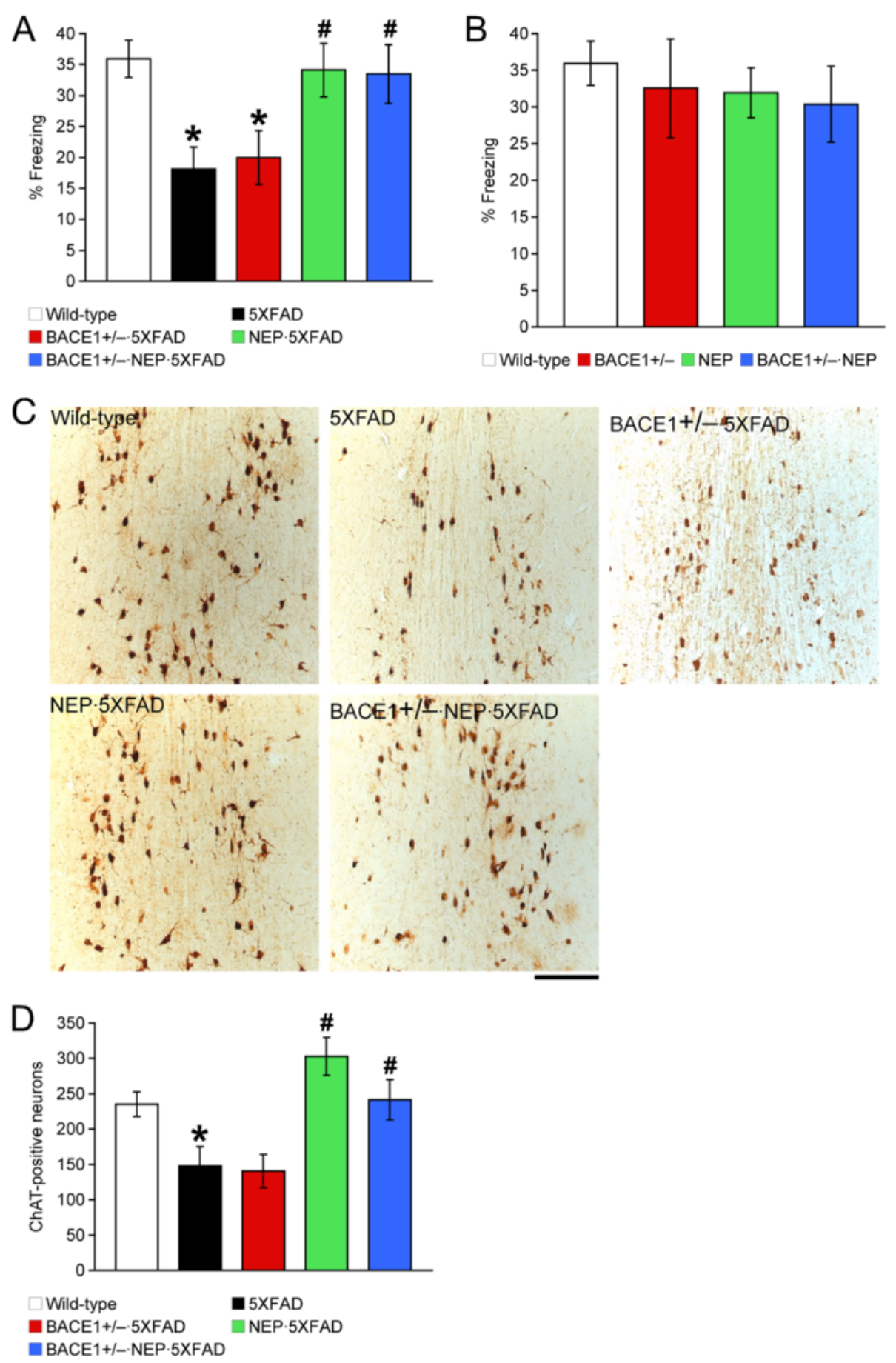

Figure 4 Effects of a combination of BACE1 haploinsufficiency and neprilysin overexpression on memory deficits and cholinergic neuron loss in 12-month-old 5XFAD mice. (A, B) Mice were trained with a CS-US pairing for contextual fear conditioning $(n=6-11$ mice per group). 5XFAD mice showed significantly lower levels of contextual freezing than wild-type mice when tested $24 \mathrm{~h}$ after training. NEP . 5XFAD and $\mathrm{BACE}^{+/-}$. NEP. 5 XFAD mice are rescued almost completely back to wild-type control levels of contextual memory. (C) Brain sections were immunostained for the cholinergic marker ChAT. Shown are representative photomicrographs of ChAT-immunoreactive neurons in the medial septum of mice. Scale bar $=200 \mu \mathrm{m}$. (D) The number of ChAT-positive neurons in the medial septum and the vertical limb of the diagonal band (Ch1/2), which provide the cholinergic innervation to the hippocampus, was counted for quantification ( $n=2-5$ mice per group). Cholinergic neuronal death associated with 5XFAD is prevented in NEP. 5XFAD and BACE $1^{+-}$. NEP. 5XFAD mice. ${ }^{*} p<0.05$ vs. wild-type, ${ }^{\#} p<0.05$ vs. 5XFAD. All data are presented as mean \pm SEM. 
the major $A \beta$-degrading enzyme neprilysin is decreased $[18,42,52]$ during disease progression in 5XFAD mouse as well as human AD brains. Our previous studies using aged 5XFAD mice have shown that a monotherapeutic $\beta$-secretase-suppressing strategy is not sufficient to surmount robust $A \beta$ accumulation, cholinergic neurodegeneration or cognitive deficits in advanced $\mathrm{AD}$ because of its failure to attenuate deleterious BACE1elevating and neprilysin-reducing mechanisms $[15,18,21]$. In this study, we tested whether a combination of boosting neprilysin and inhibiting BACE1 activities may provide a useful approach to synergistically improve $\beta$-amyloidosis and memory deficits in 5XFAD mice already suffering from extensive plaque pathology. Consistent with previous results $[15,16,18]$, BACE1 haploinsufficiency was no longer able to exert any beneficial effects in 5XFAD mice at 12 months of age. In contrast, transgenic overexpression of neprilysin in combination with BACE1 haploinsufficiency showed almost complete rescues of memory deficits of 5XFAD mice as assessed by the hippocampusdependent contextual fear conditioning and their cholinergic neuron death in the medial septum. However, we also found that transgenic overexpression of neprilysin alone sufficed to exert similar beneficial or neuroprotective effects in aged 5XFAD mice. This can be accounted for by the findings that neprilysin overexpression was so robust ( $\sim 8$-fold higher than nontransgenic controls) that it almost completely prevented plaque development in the hippocampus and cerebral cortex of 5XFAD mice concomitant with significant reductions of total $A \beta 42$ irrespective of the presence of $B A C E 1^{+/-}$gene deletion. Our observation is in agreement with previous work that showed greatly reduced plaque burden in hAPP-J20 mice crossbred with the same neprilysin transgenic line [29,30]. Collectively, it seems likely that strong $A \beta$-removing effects of overexpressed neprilysin in 5XFAD mice do not allow us to demonstrate the advantage of combining BACE1 reduction and neprilysin upregulation (if any) in further facilitating the beneficial outcomes.

Given that soluble $A \beta$ oligomers may represent toxic mediators of synaptic and mnemonic failure in $\mathrm{AD}$ [53-55], we further compared changes in oligomeric forms of $A \beta$. Levels of $A \beta$ oligomers were also significantly and equivalently reduced in NEP.5XFAD and $\mathrm{BACE}^{+/-}$. NEP . 5XFAD mice, both of which showed memory improvements. Interestingly, we found that although $\mathrm{BACE}^{+/-}$. 5XFAD mice failed to exhibit significant mitigation of total $A \beta$ accumulation or plaque pathology, similar levels of oligomer reductions occurred in brains of these mice, probably reflecting a consequence of lower BACE1-dependent $\mathrm{A} \beta$ production. Nevertheless, memory function remained deteriorated in $\mathrm{BACE}^{+/-}$. 5XFAD mice, suggesting that it is important to reduce both soluble $A \beta$ oligomers and deposited insoluble $A \beta$ species for the success of therapeutic interventions. This view is supported by accumulating evidence that indicates that $A \beta$ plaques induce structural and functional disruption of neuron networks [56-60].

It should also be noted that there is some discrepancy concerning the relationship between neprilysin overexpression and improvements of hippocampus-dependent memory deficits in $\mathrm{AD}$ mouse models in spite of the consistent abolishment of plaque formation. Meilandt et al. [30] reported that transgenic overexpression of neprilysin under the $\alpha$ CaMKII promoter did not reduce pathogenic $A \beta$ oligomers such as trimers and dodecamers $\left(A \beta^{*} 56\right)$ in hAPP-J20 mice and thus failed to rescue spatial learning and memory deficits in the Morris water maze. In contrast, we showed that neprilysin overexpression in the same transgenic line significantly lowered $A \beta$ oligomers and ameliorated contextual fear memory impairments in 5XFAD mice. Likewise, neprilysin overexpression under the PrP promoter in hAPP-J20 mice [61] or through the lentiviral vector-mediated gene transfer in APPswe/PS1dE9 mice [62] has been found to rescue spatial memory declines in the water maze, although $A \beta$ oligomer levels were not measured in these studies. Conceivably, the controversial results may arise form different approaches used to overexpress neprilysin (e.g., the onset, amounts, neuronal populations of overexpression, etc.), AD mouse models applied and behavioral tasks. However, it is most likely that reductions of soluble $A \beta$ oligomers in our NEP - 5XFAD model, despite the potential inability of neprilysin to directly degrade such $A \beta$ assemblies [29], may be attributable to reduced de novo $\mathrm{A} \beta$ generation (via blocking BACE1-elevating mechanisms, as discussed below in more detail), leading to memory improvements in conjunction with the prevention of plaque deposition.

Although the degrees of $A \beta$ reductions, mnemonic amelioration and neuronal protection were indistinguishable between NEP.5XFAD and $\mathrm{BACE}^{+/-} \cdot \mathrm{NEP}$. 5XFAD mice, we found the advantage of combining BACE1 haploinsufficiency and neprilysin overexpression in more robustly suppressing the $\beta$-amyloidogenic processing of APP. Translational elevations of BACE1 expression ( $\sim 2$ folds relative to wild-type control levels) occurred in 12-month-old 5XFAD mice through overactivation of the eIF2 $\alpha$ phosphorylation pathway, as reported previously $[15,18,22,24,40,42]$. Haploinsufficiency lowered BACE1 expression by $\sim 50 \%$ in concordance with the reduction of gene copy number, while eIF $2 \alpha$ phosphorylation was not affected and consequently BACE1 remained upregulated (i.e., equivalent to wildtype levels in spite of the ablation of a single BACE1 allele) in $\mathrm{BACE1}^{+/-} \cdot 5 \mathrm{XFAD}$ mice. Interestingly, we found that translational elevation of BACE1 was completely blocked concomitant with a significant reduction 
of eIF2 $\alpha$ phosphorylation in NEP - 5XFAD mice. This observation is consistent with our recent evidence directly demonstrating that genetic inhibition of the PERKmediated eIF $2 \alpha$ phosphorylation pathway can reverse BACE1 upregulation in 5XFAD mice [42,43]. It has been proposed that $A \beta$ accumulation induces BACE1 elevation in neurons in the close vicinity of plaques, which in turn further accelerates $\mathrm{A} \beta$ generation and plaque growth in 5XFAD mouse as well as human AD brains [22-26]. Therefore, it is conceivable that $A \beta$-degrading effects of overexpressed neprilysin prevent $A \beta$ accumulation in 5XFAD brains, thereby suppressing the eIF $2 \alpha$ phosphorylation-dependent upregulation of BACE1 expression associated with plaques. More importantly, we demonstrate that neprilysin overexpression in combination with BACE1 haploinsufficiency in 5XFAD mice almost completely abolishes eIF $2 \alpha$ phosphorylation, resulting in BACE1 expression below wild-type controls in $B A C E 1^{+/-}$. NEP - 5XFAD mice as expected by a single BACE1 allele ablation under the reversal of translational upregulation.

\section{Conclusions}

The present study shows that transgenic overexpression of neprilysin is sufficient to reduce $A \beta$ accumulation and almost completely prevent cholinergic neuron loss and memory deficits in aged 5XFAD mice. Accordingly, there is no significant difference in AD-like phenotypes between NEP.5XFAD and $\mathrm{BACE}^{+/-} \cdot \mathrm{NEP} \cdot 5 \mathrm{XFAD}$ mice. In the experimental setting with robust neprilysin overexpression ( 8-fold), it seems difficult to unequivocally demonstrate the advantage of combining partial BACE1 inhibition and neprilysin upregulation in further facilitating their beneficial outcomes during advanced stages of $\mathrm{AD}$. However, the results presented here provide clear evidence that boosting neprilysin-dependent degradation of $A \beta$ can block BACE1-elevating signaling mechanisms associated with progressive plaque formation in 5XFAD mice. Consequently, BACE1 expression and the direct $\beta$-metabolite of APP (C99) in $\mathrm{BACE}^{+/-} \cdot \mathrm{NEP} \cdot 5 \mathrm{XFAD}$ mice are further reduced to the levels reflecting a combination of single BACE1 allele ablation $\left(\mathrm{BACE}^{+/-}\right.$) and the abolishment of translational BACE1 upregulation (NEP). These findings suggest that activation of neprilysin function may be useful for complementing the limited efficacy of direct BACE1 suppression in reducing $\beta$-amyloidogenic processing of APP in advanced AD. This is quite important given that over-inhibition of $\beta$-secretase activities is suggested to induce potentially mechanism-based adverse effects on the basis of an increased number of novel BACE1 substrates that have been discovered beside APP $[4,5,63,64]$. Our gene-based findings warrant further mechanistic investigations of synergistic benefits that may be brought about by combined treatments with $\beta$-secretase inhibitors (e.g., GRL-8234 and TAK-070) [19-21] and feasible therapeutic agents capable of moderately increasing neprilysin expression or activities (e.g., $\gamma$-hydroxybutyrate) [65] in animal models relevant to later phases of $\mathrm{AD}$ with established $A \beta$ pathology.

\section{Methods}

\section{Subjects}

We used 5XFAD mice (Tg6799 line) that co-overexpress FAD mutant forms of human APP (Swedish mutation: K670N, M671L; Florida mutation: I716V; London mutation: V717I) and PS1 (M146L and L286V mutations) transgenes under transcriptional control of the neuron-specific Thy-1 promoter [9,10,31]. Hemizygous 5XFAD transgenic mice (C57Bl/6 background) were bred to heterozygous BACE1 knockout $\left(\mathrm{BACE}^{+/-}\right)$mice (C57Bl/6 background) (Stock number: 004714, The Jackson Laboratory, Bar Harbor, ME, USA) [11,66] to obtain bigenic mice with the $\mathrm{BACE}^{+/-} \cdot 5 \mathrm{XFAD}^{+/-}$ genotype. $\mathrm{BACE1}^{+/-} \cdot 5 \mathrm{XFAD}^{+/-}$mice were further crossbred to hemizygous neprilysin transgenic mice (C57Bl/6 background) (Stock number: 005086, The Jackson Laboratory) that overexpress human neprilysin under control of the $\alpha$ CaMKII promoter [29,30], yielding animals with the genotypes of interest. Genotyping was performed by PCR analysis of tail DNA. All experiments were done blind with respect to the genotype of mice at 12 months of age when 5XFAD control mice showed extensive $A \beta$ plaque pathology that was accompanied by significant BACE1 elevation and neprilysin reduction and no longer responsive to mitigation by partial BACE1 suppression $[15,16,18,21]$. Procedures were conducted in accordance with the National Institutes of Health Guide for the Care and Use of Laboratory Animals and approved by the Nathan Kline Institute Animal Care and Use Committee.

\section{Contextual fear conditioning}

Contextual fear conditioning was tested as described previously $[14,32,67]$. In this behavioral assay, mice learn to associate a distinct context (CS: conditioned stimulus) with aversive footshock (US: unconditioned stimulus) through hippocampus-dependent mechanisms $[68,69]$. During training, mice were placed in the conditioning chamber for $3 \mathrm{~min}$ and then received a footshock $(0.8 \mathrm{~mA}, 2 \mathrm{~s})$. After the shock delivery, mice were left in the chamber for another $30 \mathrm{~s}$. Contextual fear memory was evaluated by scoring freezing behavior (the absence of all movement except for that needed for breathing) for $3 \mathrm{~min}$ when the mice were placed back into the same conditioning chamber $24 \mathrm{~h}$ after training. The automated FreezeFrame system (Coulbourn Instruments, Allentown, PA, USA) was used to score the amount of 
freezing. After behavioral testing, some mice were sacrificed for immunoblotting and ELISA experiments, and others were perfused for immunohistochemistry.

\section{Immunoblot analysis}

Hemibrain samples were taken from the mice under deep isoflurane anesthesia and were snap-frozen for biochemical assays. For western blot analysis, each sample was homogenized in 8-fold volumes of cold homogenization medium containing $70 \mathrm{mM}$ sucrose, $210 \mathrm{mM}$ mannitol, $2 \mathrm{mM}$ HEPES, $0.1 \mathrm{mM}$ EDTA and protease/phosphatase inhibitor cocktail and centrifuged at $10,000 \mathrm{~g}$ for $10 \mathrm{~min}$ to remove any insoluble material. Protein concentrations were determined by a BCA protein assay kit (Pierce, Rockford, IL, USA), and 10-50 $\mu \mathrm{g}$ of protein was run on NuPAGE $4-12 \%$ or $10 \%$ Bis-Tris gels (Invitrogen, Carlsbad, CA, USA) and transferred to nitrocellulose membrane. After blocking, membranes were probed with the following primary antibodies: anti-neprilysin (1:1,000, ab951, Abcam, Cambridge, MA, USA), anti-BACE1 (1:1,000, B0681, Sigma-Aldrich, St. Louis, MO, USA), an antibody that recognizes Cterminal epitope in APP $(1: 1,000, \mathrm{C} 1 / 6.1$, kindly provided by Dr. Paul Mathews, Nathan Kline Institute) to detect full-length APP/C-terminal fragments, antiphospho-eIF2 $\alpha$ (Ser51) (1:1,000, \#3398, Cell Signaling Technology, Danvers, MA, USA), anti-eIF2 $\alpha$ (1:2,000, \#9722, Cell Signaling Technology), and anti- $\beta$-actin (1:15,000, AC-15, Sigma-Aldrich). They were then incubated with horseradish peroxidase-conjugated secondary IgG. Immunoblot signals were visualized by an ECL chemiluminescence substrate reagent kit (Pierce) and quantified by densitometric scanning and image analysis using Quantity One software (Bio-Rad Laboratories, Hercules, CA, USA). Duplicates of each sample in immunoblot assays were averaged for comparison between groups.

\section{ELISAs of soluble $A \beta$ oligomers and total $A \beta 42$}

To measure the concentrations of soluble $A \beta$ oligomers, each hemibrain sample was homogenized in 8-fold volumes of homogenization medium, as described above. To quantitate total levels of $A \beta 42$, the other hemibrain was extracted in 8-fold volumes of cold $5 \mathrm{M}$ guanidine $\mathrm{HCl}$ plus $50 \mathrm{mM}$ Tris $\mathrm{HCl}(\mathrm{pH}$ 8.0) buffer and centrifuged at $20,000 \mathrm{~g}$ for $1 \mathrm{~h}$ at $4^{\circ} \mathrm{C}$ to remove insoluble material. Final guanidine $\mathrm{HCl}$ concentrations were below $0.1 \mathrm{M}$. Protein concentrations were determined by a BCA protein assay kit (Pierce). Supernatant fractions were analyzed by well-established human $A \beta$ ELISA kits specific to oligomeric forms of $A \beta$ (27725, IBL America, Minneapolis, MN, USA) and A 342 (KHB3441, Invitrogen) according to the protocols of the manufacturers. Optical densities at $450 \mathrm{~nm}$ of each well were read on a VersaMax tunable microplate reader (Molecular Devices, Sunnyvale, CA, USA), and sample A $\beta$ oligomer and $A \beta 42$ concentrations were determined by comparison with the respective standard curves. $A \beta$ oligomer and A $\beta 42$ concentration values were normalized to total brain protein concentrations and expressed in picograms and nanograms per milligram of total protein, respectively.

\section{$A \beta$ immunohistochemistry}

Mice were transcardially perfused with $0.1 \mathrm{M}$ phosphate buffered saline (PBS, pH7.4), followed by $4 \%$ paraformaldehyde in PBS under deep isoflurane anesthesia. Brains were postfixed for $24 \mathrm{~h}$ in $4 \%$ paraformaldehyde in PBS at $4^{\circ} \mathrm{C}$ and transferred to PBS. The brain was sectioned coronally at $30 \mu \mathrm{m}$ using a vibratome (VT1200, Leica Microsystems, Wetzlar, Germany), and successive sections were stored in PBS containing $0.05 \%$ sodium azide at $4^{\circ} \mathrm{C}$. Three sections per mouse taken at levels between -1.7 and $-1.9 \mathrm{~mm}$ to bregma according to the mouse brain atlas of Franklin and Paxinos [70] were stained by the avidin-biotin peroxidase complex (ABC) method as described previously $[13,14,71]$. Briefly, the sections were incubated overnight at $4^{\circ} \mathrm{C}$ with mouse monoclonal anti-A $\beta 1-16$ (6E10) antibody (1:200, SIG39347; Covance, Princeton, NJ, USA). The ABC kit (PK-2200; Vector Laboratories, Burlingame, CA, USA) was utilized with 3,3'-diaminobenzidine tetrahydrochloride $(D A B)$ as a chromogen to visualize the reaction product. The sections were then mounted on charged slides, dehydrated in a series of alcohol, cleared in xylene and covered with a coverslip. Light microscopy was conducted on an Axioskop 2 microscope equipped with an AxioCaM HRc digital camera (Zeiss, Oberkochen, Germany) for capturing images. Semi-quantitative analysis was performed using AxioVision imaging software with the AutoMeasure module (Zeiss). The threshold optical density that discriminated staining from background was determined and held constant for all quantifications. Identified objects were individually inspected by the same investigator to confirm the object as a plaque or not in a blinded manner. Percentage area occupied by A $\beta$ deposits in the hippocampus and cortex was assessed bilaterally to compare plaque burdens between groups.

\section{ChAT immunohistochemistry}

Three brain sections per mouse were stained by the ABC method for immunohistochemical analysis of ChAT-positive neurons in the Ch1/2 comprising the medial septum and the vertical limb of the diagonal band, as described [15]. The sections were taken at levels between +1.2 and $+0.8 \mathrm{~mm}$ to bregma according to the atlas of Franklin and Paxinos [70] and incubated overnight at $4^{\circ} \mathrm{C}$ with polyclonal goat anti-ChAT antibody (1:200; AB144P, Millipore, Billerica, MA, USA). The 
$\mathrm{DAB}$ staining was performed using the $\mathrm{ABC}$ kit (PK6105, Vector Laboratories). After identified objects, following thresholding under an Axioskop 2 microscope (Zeiss), were individually inspected in a blinded manner to confirm the object as a neuron or not, the number of ChAT-positive neurons in the Ch1/2 was counted using AxioVision imaging software (Zeiss). The average of ChAT-positive neuron number per section from each mouse was used to calculate group medians.

\section{Statistical analysis}

Significant differences between the groups were determined by a one-way ANOVA and post-hoc Fisher's PLSD tests were applied following all ANOVAs showing significance. Data were presented as mean \pm SEM and the level of significance was set for $p$ value less than 0.05 .

\section{Competing interests}

The authors declare that they have no competing interests.

\section{Authors' contributions}

$\mathrm{MO}$ designed the study. LD and MO performed the experiments, analyzed the data and wrote the manuscript. All authors read and approved the final manuscript.

\section{Acknowledgements}

This work was supported by the Alzheimer's Art Quilt Initiative grant (M.O.) and the National Institutes of Health grant AG044703 (M.O.).

\section{Received: 30 January 2015 Accepted: 11 March 2015}

Published online: 25 March 2015

\section{References}

1. Vassar R. The $\beta$-secretase, BACE: a prime drug target for Alzheimer's disease. J Mol Neurosci. 2001;17:157-70

2. Hardy JA, Higgins GA. Alzheimer's disease: the amyloid cascade hypothesis. Science. 1992:256:184-5.

3. Hardy J, Selkoe DJ. The amyloid hypothesis of Alzheimer's disease: progress and problems on the road to therapeutics. Science. 2002;297:353-6.

4. Ohno M. Genetic and pharmacological basis for therapeutic inhibition of $\beta$ - and $\gamma$-secretases in mouse models of Alzheimer's memory deficits. Rev Neurosci. 2006;17:429-54

5. Ohno M. $\beta$-Secretase as a prime therapeutic target for Alzheimer's disease: a perspective from mouse model studies. In: Araki W, editor. Recent Advances in the Biology of Secretases, Key Proteases in Alzheimer's Disease. Kerala: Research Signpost; 2008. p. 1-25.

6. Cole SL, Vassar R. The Alzheimer's disease $\beta$-secretase enzyme, BACE1. Mol Neurodegener. 2007:2:22

7. Vassar R, Kovacs DM, Yan R, Wong PC. The $\beta$-secretase enzyme BACE in health and Alzheimer's disease: regulation, cell biology, function, and therapeutic potential. J Neurosci. 2009;29:12787-94.

8. Ohno M, Sametsky EA, Younkin LH, Oakley H, Younkin SG, Citron M, et al. BACE1 deficiency rescues memory deficits and cholinergic dysfunction in a mouse model of Alzheimer's disease. Neuron. 2004;41:27-33.

9. Ohno M, Chang L, Tseng W, Oakley H, Citron M, Klein WL, et al. Temporal memory deficits in Alzheimer's mouse models: rescue by genetic deletion of BACE1. Eur J Neurosci. 2006;23:251-60.

10. Ohno M, Cole SL, Yasvoina M, Zhao J, Citron M, Berry R, et al. BACE1 gene deletion prevents neuron loss and memory deficits in 5XFAD APP/PS1 transgenic mice. Neurobiol Dis. 2007;26:134-45.

11. Laird FM, Cai H, Savonenko AV, Farah MH, He K, Melnikova T, et al. BACE1, a major determinant of selective vulnerability of the brain to amyloid- $\beta$ amyloidogenesis, is essential for cognitive, emotional, and synaptic functions. J Neurosci. 2005;25:11693-709.
12. McConlogue L, Buttini M, Anderson JP, Brigham EF, Chen KS, Freedman SB, et al. Partial reduction of BACE1 has dramatic effects on Alzheimer plaque and synaptic pathology in APP transgenic mice. J Biol Chem. 2007;282:26326-34.

13. Devi L, Ohno M. Genetic reductions of $\beta$-site amyloid precursor proteincleaving enzyme 1 and amyloid- $\beta$ ameliorate impairment of conditioned taste aversion memory in 5XFAD Alzheimer's disease model mice. Eur J Neurosci. 2010;31:110-8.

14. Kimura R, Devi L, Ohno M. Partial reduction of BACE1 improves synaptic plasticity, recent and remote memories in Alzheimer's disease transgenic mice. J Neurochem. 2010;113:248-61.

15. Devi L, Ohno M. Phospho-elF2a level is important for determining abilities of $B A C E 1$ reduction to rescue cholinergic neurodegeneration and memory defects in 5XFAD mice. PLoS One. 2010;5:e12974.

16. Devi L, Ohno M. Mitochondrial dysfunction and accumulation of the $\beta$-secretase-cleaved C-terminal fragment of APP in Alzheimer's disease transgenic mice. Neurobiol Dis. 2012;45:417-24

17. Chabrier MA, Blurton-Jones M, Agazaryan AA, Nerhus JL, Martinez-Coria H, Laferla FM. Soluble Aß promotes wild-type tau pathology in vivo. J Neurosci. 2012;32:17345-50.

18. Devi L, Ohno M. Mechanisms that lessen benefits of $\beta$-secretase reduction in a mouse model of Alzheimer's disease. Transl Psychiatry. 2013:3:e284.

19. Fukumoto $H$, Takahashi H, Tarui N, Matsui J, Tomita T, Hirode M, et al. A noncompetitive BACE1 inhibitor TAK-070 ameliorates Aß pathology and behavioral deficits in a mouse model of Alzheimer's disease. J Neurosci. 2010;30:11157-66.

20. Chang WP, Huang X, Downs D, Cirrito JR, Koelsch G, Holtzman DM, et al. $\beta$-Secretase inhibitor GRL-8234 rescues age-related cognitive decline in APP transgenic mice. FASEB J. 2011;25:775-84.

21. Devi L, Tang J, Ohno M. Beneficial effects of the $\beta$-secretase inhibitor GRL-8234 in 5XFAD Alzheimer's transgenic mice lessen during disease progression. Curr Alzheimer Res. 2015;12:13-21.

22. Zhao J, Fu Y, Yasvoina M, Shao P, Hitt B, O'Connor T, et al. $\beta$-Site amyloid precursor protein cleaving enzyme 1 levels become elevated in neurons around amyloid plaques: implications for Alzheimer's disease pathogenesis. J Neurosci. 2007;27:3639-49.

23. Zhang X-M, Cai Y, Xiong K, Cai H, Luo X-G, Feng J-C, et al. $\beta$-Secretase-1 elevation in transgenic mouse models of Alzheimer's disease is associated with synaptic/axonal pathology and amyloidogenesis: implications for neuritic plaque development. Eur J Neurosci. 2009;30:2271-83.

24. Devi L, Ohno M. Deletion of the elF2a kinase GCN2 fails to rescue the memory decline associated with Alzheimer's disease. PLoS One. 2013:8:e77335.

25. Leroy K, Ando K, Laporte V, Dedecker R, Suain V, Authelet M, et al. Lack of tau proteins rescues neuronal cell death and decreases amyloidogenic processing of APP in APP/PS1 mice. Am J Pathol. 2012;181:1928-40.

26. Kandalepas PC, Sadleir KR, Eimer WA, Zhao J, Nicholson DA, Vassar R. The Alzheimer's $\beta$-secretase BACE1 localizes to normal presynaptic terminals and to dystrophic presynaptic terminals surrounding amyloid plaques. Acta Neuropathol. 2013;126:329-52.

27. Huang SM, Mouri A, Kokubo H, Nakajima R, Suemoto T, Higuchi M, et al Neprilysin-sensitive synapse-associated amyloid- $\beta$ peptide oligomers impair neuronal plasticity and cognitive function. J Biol Chem. 2006;281:17941-51.

28. Farris W, Schutz SG, Cirrito JR, Shankar GM, Sun X, George A, et al. Loss of neprilysin function promotes amyloid plaque formation and causes cerebral amyloid angiopathy. Am J Pathol. 2007;171:241-51.

29. Leissring MA, Farris W, Chang AY, Walsh DM, Wu X, Sun X, et al. Enhanced proteolysis of $\beta$-amyloid in APP transgenic mice prevents plaque formation, secondary pathology, and premature death. Neuron. 2003;40:1087-93.

30. Meilandt WJ, Cisse M, Ho K, Wu T, Esposito LA, Scearce-Levie K, et al. Neprilysin overexpression inhibits plaque formation but fails to reduce pathogenic $A \beta$ oligomers and associated cognitive deficits in human amyloid precursor protein transgenic mice. J Neurosci. 2009;29:1977-86.

31. Oakley H, Cole SL, Logan S, Maus E, Shao P, Craft J, et al. Intraneuronal $\beta$-amyloid aggregates, neurodegeneration, and neuron loss in transgenic mice with five familial Alzheimer's disease mutations: potential factors in amyloid plaque formation. J Neurosci. 2006;26:10129-40.

32. Kimura R, Ohno M. Impairments in remote memory stabilization precede hippocampal synaptic and cognitive failures in 5XFAD Alzheimer mouse model. Neurobiol Dis. 2009;33:229-35.

33. Ohno M. Failures to reconsolidate memory in a mouse model of Alzheimer's disease. Neurobiol Learn Mem. 2009:92:455-9. 
34. Jawhar S, Trawicka A, Jenneckens C, Bayer TA, Wirths O. Motor deficits, neuron loss, and reduced anxiety coinciding with axonal degeneration and intraneuronal A $\beta$ aggregation in the 5XFAD mouse model of Alzheimer's disease. Neurobiol Aging. 2012;33:196.e129-40.

35. Chen R, Zhang J, Wu Y, Wang D, Feng G, Tang YP, et al. Monoacylglycerol lipase is a therapeutic target for Alzheimer's disease. Cell Rep. 2012;2:1329-39

36. Hongpaisan J, Sun MK, Alkon DL. PKC \& Activation Prevents Synaptic Loss, $A \beta$ Elevation, and Cognitive Deficits in Alzheimer's Disease Transgenic Mice. J Neurosci. 2011;31:630-43.

37. Zhang Z, Liu X, Schroeder JP, Chan CB, Song M, Yu SP, et al. 7,8Dihydroxyflavone prevents synaptic loss and memory deficits in a mouse model of Alzheimer's disease. Neuropsychopharmacology. 2014:39:638-50.

38. Seo J, Giusti-Rodriguez P, Zhou Y, Rudenko A, Cho S, Ota KT, et al. Activitydependent p25 generation regulates synaptic plasticity and Aß-induced cognitive impairment. Cell. 2014;157:486-98.

39. Chang RC, Wong AK, Ng HK, Hugon J. Phosphorylation of eukaryotic initiation factor-2a (elF2a) is associated with neuronal degeneration in Alzheimer's disease. Neuroreport. 2002;13:2429-32.

40. O'Connor T, Sadleir KR, Maus E, Velliquette RA, Zhao J, Cole SL, et al. Phosphorylation of the translation initiation factor elF2a increases BACE1 levels and promotes amyloidogenesis. Neuron. 2008;60:988-1009.

41. Mouton-Liger F, Paquet C, Dumurgier J, Bouras C, Pradier L, Gray F, et al. Oxidative stress increases BACE1 protein levels through activation of the PKR-elF2a pathway. Biochim Biophys Acta. 1822;2012:885-96.

42. Devi L, Ohno M. PERK mediates elF2a phosphorylation responsible for BACE1 elevation, CREB dysfunction and neurodegeneration in a mouse model of Alzheimer's disease. Neurobiol Aging. 2014;35:2272-81.

43. Ohno M. Roles of elF2a kinases in the pathogenesis of Alzheimer's disease. Front Mol Neurosci. 2014;7:22.

44. Holsinger RM, McLean CA, Beyreuther K, Masters CL, Evin G. Increased expression of the amyloid precursor $\beta$-secretase in Alzheimer's disease. Ann Neurol. 2002;51:783-6.

45. Borghi R, Patriarca S, Traverso N, Piccini A, Storace D, Garuti A, et al. The increased activity of BACE1 correlates with oxidative stress in Alzheimer's disease. Neurobiol Aging. 2007;28:1009-14.

46. Gale GD, Anagnostaras SG, Fanselow MS. Cholinergic modulation of pavlovian fear conditioning: effects of intrahippocampal scopolamine infusion. Hippocampus. 2001;11:371-6.

47. Choi JH, Kaur G, Mazzella MJ, Morales-Corraliza J, Levy E, Mathews PM. Early endosomal abnormalities and cholinergic neuron degeneration in amyloid- $\beta$ protein precursor transgenic mice. J Alzheimers Dis. 2013;34:691-700.

48. Saido TC, Leissring MA. Proteolytic degradation of amyloid- $\beta$ protein. In: Selkoe DJ, Mandelkow E, Holtzman DM, editors. The Biology of Alzheimer Disease. Cold Spring Harbor: Cold Spring Harbor Laboratory Press; 2012. p. 387-404

49. Mawuenyega KG, Sigurdson W, Ovod V, Munsell L, Kasten T, Morris JC, et al. Decreased clearance of CNS $\beta$-amyloid in Alzheimer's disease. Science. 2010;330:1774.

50. Fukumoto $\mathrm{H}$, Cheung BS, Hyman BT, Irizarry MC. $\beta$-Secretase protein and activity are increased in the neocortex in Alzheimer disease. Arch Neurol. 2002;59:1381-9.

51. Yang LB, Lindholm K, Yan R, Citron M, Xia W, Yang XL, et al. Elevated $\beta$-secretase expression and enzymatic activity detected in sporadic Alzheimer disease. Nat Med. 2003;9:3-4.

52. Wang S, Wang R, Chen L, Bennett DA, Dickson DW, Wang DS. Expression and functional profiling of neprilysin, insulin-degrading enzyme, and endothelin-converting enzyme in prospectively studied elderly and Alzheimer's brain. J Neurochem. 2010;115:47-57.

53. Haass C, Selkoe DJ. Soluble protein oligomers in neurodegeneration: lessons from the Alzheimer's amyloid $\beta$-peptide. Nat Rev Mol Cell Biol. 2007:8:101-12.

54. Shankar GM, Walsh DM. Alzheimer's disease: synaptic dysfunction and Aß. Mol Neurodegener. 2009;4:48

55. Ferreira ST, Klein WL. The A oligomer hypothesis for synapse failure and memory loss in Alzheimer's disease. Neurobiol Learn Mem. 2011;96:529-43.

56. Tsai J, Grutzendler J, Duff K, Gan WB. Fibrillar amyloid deposition leads to local synaptic abnormalities and breakage of neuronal branches. Nat Neurosci. 2004;7:1181-3.
57. Busche MA, Eichhoff $G$, Adelsberger $H$, Abramowski D, Wiederhold KH, Haass $C$, et al. Clusters of hyperactive neurons near amyloid plaques in a mouse model of Alzheimer's disease. Science. 2008;321:1686-9.

58. Kuchibhotla KV, Goldman ST, Lattarulo CR, Wu HY, Hyman BT, Bacskai BJ. Aß plaques lead to aberrant regulation of calcium homeostasis in vivo resulting in structural and functional disruption of neuronal networks. Neuron. 2008:59:214-25.

59. Meyer-Luehmann M, Spires-Jones TL, Prada C, Garcia-Alloza M, De Calignon A, Rozkalne A, et al. Rapid appearance and local toxicity of amyloid- $\beta$ plaques in a mouse model of Alzheimer's disease. Nature. 2008;451:720-4.

60. Stern EA, Bacskai BJ, Hickey GA, Attenello FJ, Lombardo JA, Hyman BT. Cortical synaptic integration in vivo is disrupted by amyloid- $\beta$ plaques. J Neurosci. 2004;24:4535-40.

61. Poirier R, Wolfer DP, Welzl H, Tracy J, Galsworthy MJ, Nitsch RM, et al. Neuronal neprilysin overexpression is associated with attenuation of Aß-related spatial memory deficit. Neurobiol Dis. 2006;24:475-83.

62. El-Amouri SS, Zhu H, Yu J, Marr R, Verma IM, Kindy MS. Neprilysin: an enzyme candidate to slow the progression of Alzheimer's disease. Am J Pathol. 2008;172:1342-54.

63. Yan R, Vassar R. Targeting the $\beta$ secretase BACE1 for Alzheimer's disease therapy. Lancet Neurol. 2014;13:319-29.

64. Vassar R, Kuhn PH, Haass C, Kennedy ME, Rajendran L, Wong PC, et al. Function, therapeutic potential and cell biology of BACE proteases: current status and future prospects. J Neurochem. 2014;130:4-28.

65. Klein C, Mathis C, Leva G, Patte-Mensah C, Cassel JC, Maitre M, et al. $\gamma$-Hydroxybutyrate (Xyrem) ameliorates clinical symptoms and neuropathology in a mouse model of Alzheimer's disease. Neurobiol Aging. 2015;36:832-44.

66. Cai H, Wang $Y$, McCarthy $D$, Wen $H$, Borchelt DR, Price $D L$, et al. BACE1 is the major $\beta$-secretase for generation of $A \beta$ peptides by neurons. Nat Neurosci. 2001:4:233-4

67. Ohno M, Frankland PW, Chen AP, Costa RM, Silva AJ. Inducible, pharmacogenetic approaches to the study of learning and memory. Nat Neurosci. 2001;4:1238-43.

68. Fanselow MS. Contextual fear, gestalt memories, and the hippocampus. Behav Brain Res. 2000;110:73-81.

69. Maren S. Neurobiology of Pavlovian fear conditioning. Annu Rev Neurosci. 2001;24:897-931.

70. Franklin KBJ, Paxinos G. The Mouse Brain in Stereotaxic Coordinates. 3rd ed. New York: Academic Press; 2008.

71. Devi L, Alldred MJ, Ginsberg SD, Ohno M. Sex- and brain region-specific acceleration of $\beta$-amyloidogenesis following behavioral stress in a mouse model of Alzheimer's disease. Mol Brain. 2010;3:34.

\section{Submit your next manuscript to BioMed Central and take full advantage of:}

- Convenient online submission

- Thorough peer review

- No space constraints or color figure charges

- Immediate publication on acceptance

- Inclusion in PubMed, CAS, Scopus and Google Scholar

- Research which is freely available for redistribution 